\title{
MODELLING MEAN ALBEDO OF INDIVIDUAL ROOFS IN COMPLEX URBAN AREAS USING SATELLITE IMAGES AND AIRBORNE LASER SCANNING POINT CLOUDS
}

\author{
B. Kalantar a*, S. Mansor ${ }^{\text {a }}$, Z. Khuzaimah ${ }^{\text {a }}$, M. Ibrahim Sameen ${ }^{\text {a }}$, B. Pradhan ${ }^{\text {a }}$ \\ ${ }^{a}$ Department of Civil Engineering, Geospatial Information Science Research Centre (GISRC), Faculty of Engineering, University \\ Putra Malaysia, Serdang, Selangor(Bahare_kgh@yahoo.com; shattri@upm.edu.my; zailanikhuzaimah@gmail.com; \\ maherrsgis@gmail.com; biswajeet24@gmail.com)
}

Commission VI, WG VI/4

KEY WORDS: Urban Climate, Surface Albedo, Roofing Materials, Object Based Image Analysis, Support Vector Machine.

\begin{abstract}
:
Knowledge of surface albedo at individual roof scale is important for mitigating urban heat islands and understanding urban climate change. This study presents a method for quantifying surface albedo of individual roofs in a complex urban area using the integration of Landsat 8 and airborne LiDAR data. First, individual roofs were extracted from airborne LiDAR data and orthophotos using optimized segmentation and supervised object based image analysis (OBIA). Support vector machine (SVM) was used as a classifier in OBIA process for extracting individual roofs. The user-defined parameters required in SVM classifier were selected using v-fold cross validation method. After that, surface albedo was calculated for each individual roof from Landsat images. Finally, thematic maps of mean surface albedo of individual roofs were generated in GIS and the results were discussed. Results showed that the study area is covered by $35 \%$ of buildings varying in roofing material types and conditions. The calculated surface albedo of buildings ranged from 0.16 to 0.65 in the study area. More importantly, the results indicated that the types and conditions of roofing materials significantly effect on the mean value of surface albedo. Mean albedo of new concrete, old concrete, new steel, and old steel were found to be equal to $0.38,0.26,0.51$, and 0.44 respectively. Replacing old roofing materials with new ones should highly prioritized.
\end{abstract}

\section{INTRODUCTION}

Global warming is the term used to describe the increase in the average temperature of the Earth's atmosphere, a change that is thought to be permanently changing the Earth's climate. Increasing the temperature of the Earth's surface cause not only thermal discomfort, but it also responsible for the increase of energy demand for air conditioning in buildings and photochemistry effects that increase atmospheric pollution, as well as increasing environmental impacts due to the demand of energy generation (Prado and Ferreira, 2005). Air temperature is higher in urban areas than in rural areas, a phenomenon called urban heat island or UHI. The effects of UHI can be reduced through changing the materials used in buildings, which in turn can lead to valuable effects for human and environment. Lowering of air temperature in urban areas, the reduction of energy demand for air conditioning systems, and the reduction of atmospheric pollution are among those valuable effects. Surface albedo, which can be calculated by remote sensing and climate data, determines the fraction of incoming sunlight that is reflected is a key factor for determining the urban heat budget and understanding UHI effects. There are two factors determining urban albedo: building structure and surface material. Urban albedo decreases with decreasing street widths and increasing building heights (Sugawara and Takamura, 2014). Increasing the surface albedo can reduce the temperature of the urban areas and consequently the UHI intensity (Touchaei and Akbari, 2013). In addition, increasing urban albedo can reduce summertime temperatures, resulting in better air quality and savings from reduced airconditioning costs. Increasing urban albedo can result in less absorption of incoming solar radiation by the surfacetroposphere system, countering to some extent the global scale effects of increasing greenhouse gas concentrations (Akbari et al., 2009). Touchaei and Akbari (2013) presented a study in which increasing the albedo of roofs from 0.2 to 0.8 decreased the average air temperature of urban areas of Montreal by $0.3 \mathrm{~K}$. Typically, surface albedo ranges from 0 , all the incident energy is absorbed to 1 , all the incident energy is reflected from the roof (Ban-Weiss et al., 2015a, 2015b). Materials with high albedo and emittance attain lower temperatures when exposed to solar radiation, reducing the transference of heat to the environmental air (Prado and Ferreira, 2005). Green roofs are highly efficient in reducing the variation of indoor temperature and decreasing the level of building energy consumption both in cold and warm climates. The albedo of green roofs ranges from 0.7 to 0.85 , a value much higher than other roofs (Berardi et al., 2014). On the other hand, a cool roof is a roof that reflects most of the incident sunlight and efficiently emits some of the absorbed radiation (especially in near infrared) back into the atmosphere, instead of conducting it to the building below (Garg et al., 2015). Green roofs and cool roofs are the two main effective solutions handling the problem of urban warming.

\section{METHODOLOGY}

\subsection{Study area}

The study area is a subset from the Universiti Putra Malaysia (UPM) campus located in peninsular (West) Malaysia. The study area is bounded between $101^{\circ} 44^{\prime} 05^{\prime \prime} \mathrm{E}$ and $101^{\circ} 44^{\prime}$ $35^{\prime \prime} \mathrm{E}, 03^{\circ} 00^{\prime} 00^{\prime \prime} \mathrm{N}$ and $03^{\circ} 00^{\prime} 35^{\prime \prime} \mathrm{N}$ as shown in Figure 1 . The study area is a complex urban area and it consists of mixed several types of roofs, urban vegetation, and asphalt roads. The study area has a surface area of $(0.53 \mathrm{~km} 2)$ with $30 \%$ is buildings and other $70 \%$ are vegetation, bare land, and asphalt 
roads. Buildings have different roofing materials with different conditions. New concrete, old concrete, new steel, old steel, and asbestos are the main roofing materials in the study area.

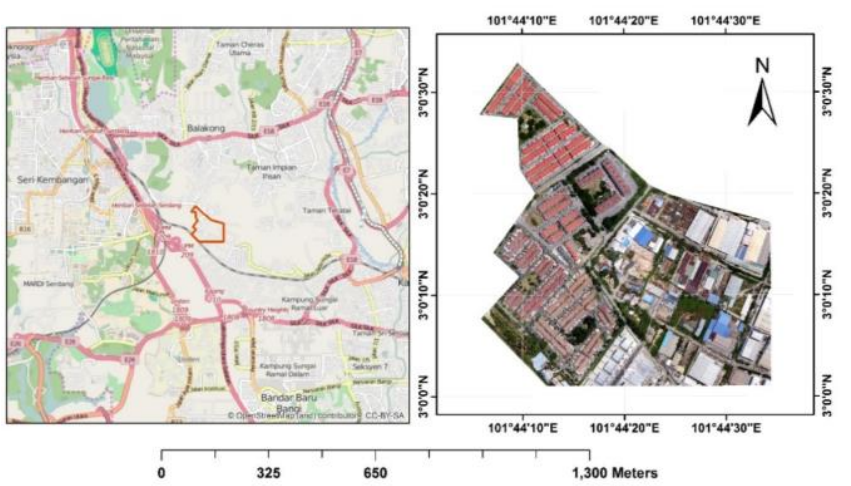

Figure 1. Location of study area presented by OpenStreetMap (left), and aerial orthophoto (right).

\subsection{Datasets}

The Landsat data (path $=127$, row $=58$ ) used in this study was collected on 27 March 2015 from the U.S. Geological Survey (USGS) official website (http://earthexplorer.usgs.gov/). The spatial resolution of Landsat 8 images is $30 \mathrm{~m}$ and it has 11 spectral bands in visible, infrared, and thermal regions. The Landsat image has the cloud cover of (19.98\%); however, the subset used in this study has no cloud cover. On the other hand, the LiDAR data used in this study was collected on 8 March 2013 by Riegl LM Q5600 and Camera Hassleblad 39Mp. The device has a spatial resolution of $13 \mathrm{~cm}$, laser scanning angle of $60^{\circ}$ and camera angle $-45^{\circ}$. In addition, the posting density of the LiDAR data was 3-4 pts $/ \mathrm{m} 2$.

\subsection{Methods}

\subsubsection{Overview}

Overall methodology applied in this study to quantify mean surface albedo of individual roofs is presented in Figure 2. First, LiDAR point clouds were processed to generate digital surface and elevation models for the study area. Then, DEM was subtracted from DSM to construct height raster (nDSM), which represents the height of objects in the study area. After that, first pulse LiDAR point clouds were then used to generate intensity raster. $\mathrm{nDSM}$, intensity raster, and three bands of aerial orthophoto were then combined in one dataset by a process called raster composite. The combined raster then was segmented to create image objects utilizing both spatial and spectral characteristics. Next, SVM was used to classify the image objects using spatial and spectral attributes. The classified buildings then were exported to ArcMap to extract the roof footprints. On the other hand, Landsat image was preprocessed to correct it for geometric, radiometric, and atmospheric errors. After that, the processed Landsat image together with climate data downloaded online was used to calculate surface albedo. Finally, the extracted footprints of roofs and calculated surface albedo were then used to calculate mean surface albedo for individual roofs using zonal statistics.

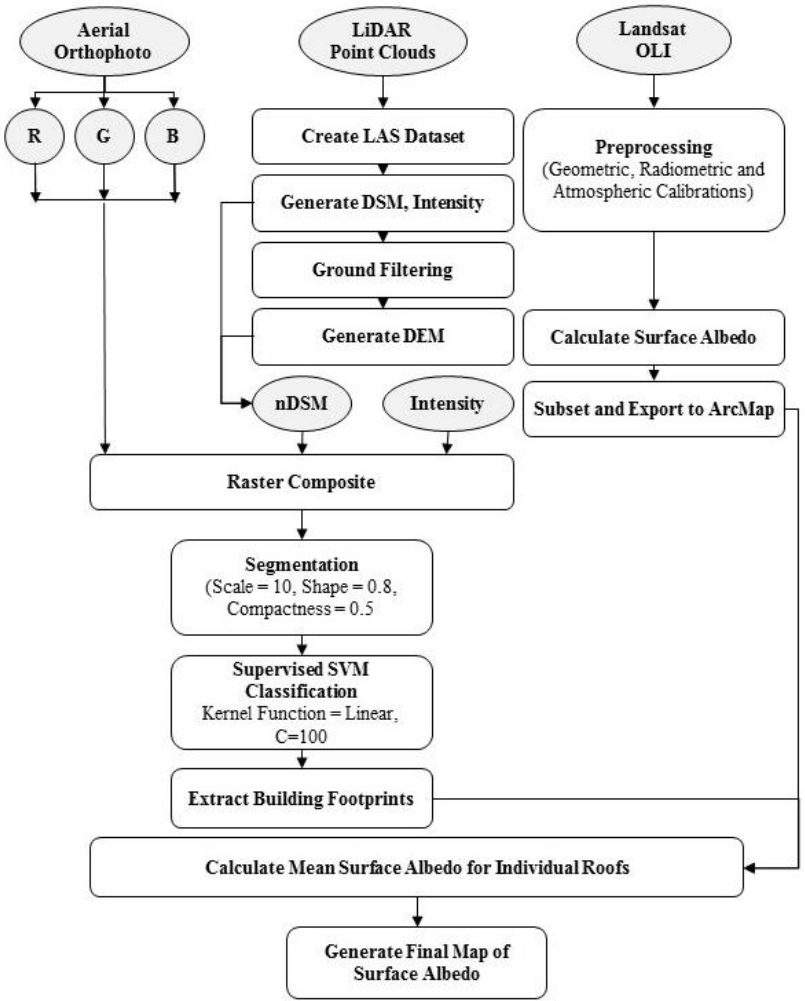

Figure 2. Overall methodology applied to quantify surface albedo of roofs in the current study.

\subsubsection{Segmentation}

In recent years, object based image analysis or OBIA has been accepted as a suitable classification technique for LiDAR data (Blaschke, 2010). OBIA has two main steps; the first is called image segmentation, which is the process of creating nonoverlapping homogeneous objects from the image pixels based on their spectral, spatial, and textural information. Usually in this step, OBIA uses multiresolution segmentation algorithm (Baatz \& Schäpe, 2000). The accuracy level of feature extraction and object classification is generally controlled by the quality of segmentation (Baatz \& Schäpe, 2000). Multiresolution segmentation algorithm requires three userdefined parameters namely scale, shape, and compactness, which control the size and shape of image objects. Therefore, selection of suitable user-defined parameters is important for accurate segmentation and building extraction from airborne LiDAR. In this study, user-defined parameters were selected using Bhattacharyya Distance algorithm (Choi and Lee, 2003). This algorithm measures the class separability distance using feature space. The scale parameters of (10), was selected based on the highest class separability distance measured (1.82) using spatial and spectral attributes. Likewise, shape and compactness parameters were selected using the same technique and values of 0.8 and 0.5 were selected for shape and compactness respectively. Using these user-defined parameters and input data derived from LiDAR point clouds (Figure 3a, 3b, 3c, 3d), the image objects were created (Figure $3 \mathrm{e}$ ). 


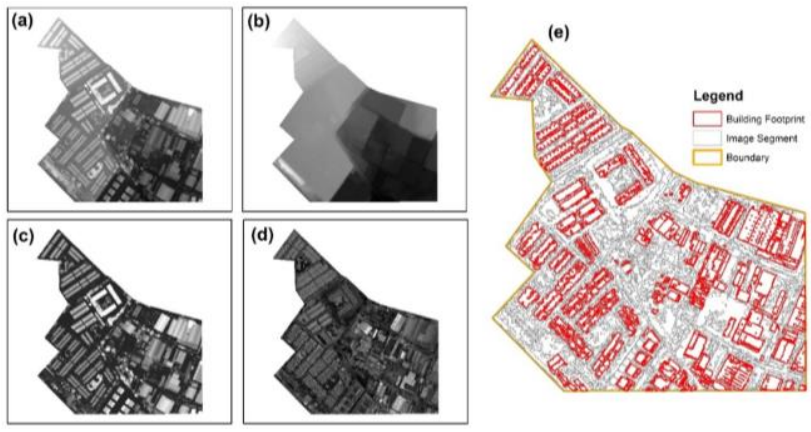

Figure 3. Input data used for building extraction and image segments, (a) LiDAR derived DSM, (b) LiDAR derived DEM, (c) Height, or nDSM, (d) Intensity, (e) Image segments and building footprints.

\subsubsection{Supervised object based SVM classification}

The second step in OBIA process is the object classification. There are mainly two types of classification for OBIA; supervised or example-based and rule-based methods. The supervised classifier based on samples objects to create training objects. Support vector machine (SVM) was used in this study to classify the image objects into four land cover, building, bare land, vegetation, and asphalt road. Two main parameters are required for SVM algorithm namely kernel function and penalty parameter (C). Careful selection of these parameters is critical for accurate classification of image objects. In this study, kernel function and $\mathrm{C}$ value were selected using v-fold cross validation method (Hsu et al., 2003). In this method, the training dataset first was divided into v subsets of equal size. Sequentially one subset is tested using the classifier trained on the remaining $\mathrm{v}$ -1 subsets. Thus, each instance of the whole training set is predicted once so the cross-validation accuracy is the percentage of data, which are correctly classified. The main advantage of this method for SVM parameter selection is that cross-validation procedure can prevent the overfitting problem. Using 10-fold cross validation, the kernel function, and $\mathrm{C}$ value of SVM algorithm were selected. Linear type of kernel function and $\mathrm{C}$ value of (100) were selected using the datasets of the current study. Once the parameters of SVM algorithm selected, image objects were then classified using training objects. In the SVM classification, several spectral and spatial attributes were used for classification. Three bands of aerial orthophoto, nDSM, intensity, rectangular fit, density, shape index attributes were used in the classification process. The classified image contained four land cover classes namely building, vegetation, bare land, and asphalt road. Overall accuracy of $(87.2 \%)$ and Kappa coefficient of (0.78) was achieved. The classified image objects were then exported to GIS in a vector form for building extraction (see Figure 3e).

\subsubsection{Calculation and mapping of individual roof surface albedo}

The surface albedo was calculated using the following equation suggested by Bastiaanssen et al. (1998).

$\alpha=\frac{\alpha_{\mathrm{tog}}-\alpha_{\mathrm{atm}}}{\tau_{\mathrm{oc}}^{2}}$ where $\alpha_{\text {tog }}$ is the planetary albedo of each pixel or albedo without atmospheric correction, $\alpha_{\mathrm{atm}}$ is the atmospheric albedo and $\tau_{\infty e}$ is the atmospheric transmittance in the solar radiation.

The value of atmospheric albedo can be obtained through a radiative transfer model and, in general, is situated between 0.025 and 0.040 (Allen et al., 2002). The value of 0.03 was adopted in the present study. On the other hand, $\alpha_{\text {tog }}$ and $\tau_{\text {oc }}$ were calculated using equations adopted from Silva et al. (2016). The calculations were done in ENVI 5.1 software using its Band Math tool. Once the surface albedo was calculated for the study area using Landsat 8 image, the result was exported to GIS for further analysis. The extracted buildings and calculated surface albedo were then used to generate surface albedo of individual roofs. Results were used to produce the final thematic map of surface albedo of individual roofs.

\section{RESULTS AND DISCUSSION}

Mean albedo of individual roofs in a complex urban area were quantified. Figure 4 shows the thematic map of mean albedo at individual roof scale generated by using the proposed method in GIS. Statistics show that the mean albedo ranges from (0 to 0.65 ) in the study area including buildings and other classes (i.e. vegetation, bare land, asphalt road). In addition, the mean albedo of buildings is ranged from (0.16 to 0.65$)$ in the study area. These variations in albedo values resulted from various types and conditions of roofing materials found in the study area.

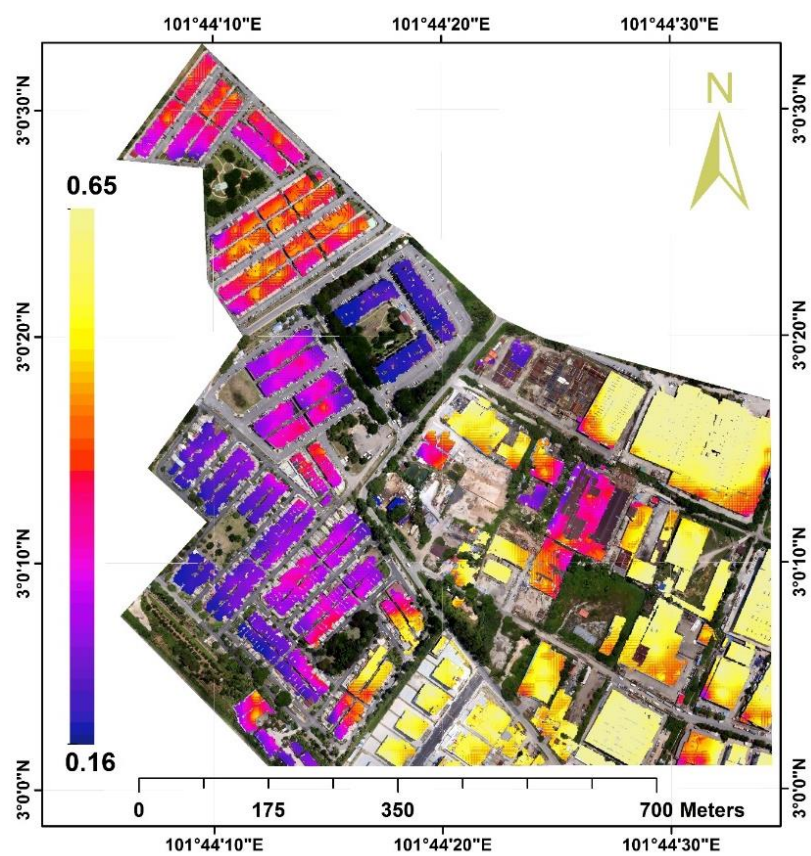

Figure 4. Surface albedo of roofs in the study area generated in GIS by the proposed method.

Table 1 presented the mean albedo calculated for each land cover class in the study area using zonal statistics in GIS. The analysis showed that building class has the highest mean albedo 
among the classes. On the other hand, the lowest mean albedo was observed for asphalt road class (0.24). The high value of standard deviation of building class (0.092) indicates that there are various types of roofs in the study area. In addition to the types of roofing materials in the study area, it was observed that the roofing materials have different conditions.

\begin{tabular}{llll}
\hline $\begin{array}{l}\text { Class } \\
\text { Name }\end{array}$ & $\begin{array}{l}\text { Surface Area } \\
(\mathrm{m} 2)\end{array}$ & Mean Albedo & $\begin{array}{l}\text { Standard } \\
\text { Deviation }\end{array}$ \\
\hline Vegetation & $125,704(23 \%)$ & 0.25 & 0.068 \\
Road & $101,029(19 \%)$ & 0.24 & 0.057 \\
Building & $187,418(35 \%)$ & 0.30 & 0.092 \\
Bare Land & $124,090(23 \%)$ & 0.27 & 0.061 \\
\hline
\end{tabular}

Table 1. Mean albedo and standard deviations of various land covers found in the study area

Table 2 shows the mean albedo of various types of roofing materials. Mean albedo of new concrete and old concrete were equal to 0.38 and 0.26 respectively. In addition, mean albedo of new steel and old steel were found to be equal to 0.51 and 0.44 respectively. Results revealed that new roofing materials could play an important role in mitigating urban warming. Therefore, replacing old materials with new materials and increasing mean albedo of roofing materials in the study area should highly prioritized.

\begin{tabular}{ll}
\hline Type of roofing material & Mean Albedo \\
\hline New Concrete & 0.38 \\
Old Concrete & 0.26 \\
New Steel & 0.51 \\
Old Steel & 0.44 \\
\hline
\end{tabular}

Table 2. Mean albedo of various types of roofing materials

\section{CONCLUSION}

Landsat OLI and airborne LiDAR were integrated to quantify mean surface albedo of individual roofs in a complex urban area. Landsat OLI was used to calculate the surface albedos while airborne LiDAR utilized to extract building footprints. Results indicated that the study area is covered by $35 \%$ of buildings varying in roofing material types and conditions. The calculated surface albedo of buildings ranged from 0.16 to 0.65 in the study area. The mean albedo of buildings was observed to be equal to 0.30 while other classes were slightly less than buildings albedo. Results showed that the proposed method is a valuable tool for decision makers and urban planners.

\section{REFERENCES}

Akbari, H., Menon, S., \& Rosenfeld, A., 2009. Global cooling: increasing world-wide urban albedos to offset $\mathrm{CO} 2$. Climatic Change, 94(3-4), 275-286.

Allen, R. G.; Tasumi, M.; Trezza, R., 2007. Satellite-based energy balance for mapping evapotranspiration with internalized calibration (METRIC) - Model. Journal of Irrigation and Drainage Engineering, v.133, p.380-394, 2007.

Baatz, M., \& Schäpe, A., 2000. Multiresolution segmentation: an optimization approach for high quality multi-scale image segmentation. Angewandte Geographische Information sverar beitung XII, 12-23.

Ban-Weiss, G. A., Woods, J., \& Levinson, R., 2015. Using remote sensing to quantify albedo of roofs in seven California cities, Part 1: Methods. Solar Energy, 115, 777-790.

Ban-Weiss, G. A., Woods, J., Millstein, D., \& Levinson, R., 2015. Using remote sensing to quantify albedo of roofs in seven California cities, Part 2: Results and application to climate modeling. Solar Energy, 115, 791-805.

Bastiaanssen, W. G. M.; Menenti, M.; Feddes, R. A.; Holslag, A. A. M. A., 1998. Remote sensing surface energy balance algorithm for land (SEBAL) - Formulation. Journal of Hydrology, v.212-213, p.198- 212.

Berardi, U., GhaffarianHoseini, A., \& GhaffarianHoseini, A., 2014. State-of-the-art analysis of the environmental benefits of green roofs. Applied Energy, 115, 411-428.

Choi, E., \& Lee, C. (2003). Feature extraction based on the Bhattacharyya distance. Pattern Recognition, 36(8), 1703-1709. Garg, V., Kotharkar, R., Sathaye, J., Rallapalli, H., Kulkarni, N., Reddy, N., ... \& Sarkar, A. (2015). Assessment of the impact of cool roofs in rural buildings in India. Energy and Buildings. Hsu, C. W., Chang, C. C., \& Lin, C. J. (2003). A practical guide to support vector classification.

Prado, R. T. A., \& Ferreira, F. L., 2005. Measurement of albedo and analysis of its influence the surface temperature of building roof materials. Energy and Buildings, 37(4), 295-300.

Silva, B. B. D., Braga, A. C., Braga, C. C., de Oliveira, L. M., Montenegro, S. M., \& Barbosa Junior, B., 2016. Procedures for calculation of the albedo with OLI-Landsat 8 images: Application to the Brazilian semi-arid. Revista Brasileira de Engenharia Agrícola e Ambiental, 20(1), 3-8.

Sugawara, H., \& Takamura, T., 2014. Surface albedo in cities: case study in Sapporo and Tokyo, Japan. Boundary-Layer Meteorology, 153(3), 539-553.

Touchaei, A. G., \& Akbari, H., 2013. The climate effects of increasing the albedo of roofs in a cold region $\uparrow$. Advances in Building Energy Research, 7(2), 186-191.

Moons, T., 1997. Report on the Joint ISPRS Commission III/IV Workshop "3D Reconstruction and Modelling of Topographic Objects", Stuttgart, Germany http://www.radig.informatik.tumuenchen.de/ISPRS/WG-III4-IV2-Report.html (28 Sep. 1999). 